\title{
ARTIGOS
}

\section{SOBRE O PRINCÍPIO E A LEI UNIVERSAL DO DIREITO EM KANT*}

\author{
Guido Antônio de Almeida ${ }^{1}$ \\ guidoalmeida@hotmail.com
}

RESUMO $O$ artigo distingue duas fórmulas do princípio do Direito em Kant; mostra que na primeira delas o Princípio Universal do Direito é formulado como um principium diiudicationis e na segunda a Lei Universal do Direito como um principium executionis das ações conforme ao Direito; examina as dificuldades suscitadas para ambas as formulações, quais sejam, a base para a definição do que é direito e a questão se as leis jurídicas têm e, caso tenham, qual é a sua força prescritiva; e, finalmente, propõe uma solução baseada na consideração de que as leis jurídicas constituem para Kant uma subclasse das leis morais e se baseiam no conceito de uma autorização ou faculdade moral de fazer o que é moralmente lícito ou obrigatório e de não fazer o que é moralmente proibido.

Palavras-chave Conceito Kantiano do Direito; Leis Morais e Leis Jurídicas; Direito e Faculdade Moral; Princípio Universal do Direito; Força Prescritiva

ABSTRACT The present paper distinguishes two formulas of the principle of Right in Kant; it shows that in one of them (the Universal Principle of Right) the principle is expressed as a principium diiudicationis and in the other (the Universal Law of Right) as a principium executionis

\footnotetext{
* O presente texto é a reelaboração de uma conferência proferida como aula inaugural do Departamento de Filosofia, na Faculdade de Filosofia e Ciências Humanas (FAFICH) da UFMG, no dia 31/03/2006.

1 Professor da Universidade Federal do Rio de Janeiro (UFRJ). Convidado a participar deste número da Kriterion.
}

KRITERION, Belo Horizonte, nº 114, Dez/2006, p. 209-222. 
of what we consider to be right; it scrutinizes difficulties involved in both formulations, in particular the basis for definition of what is considered right and the prescriptive force of the Universal Law of Right; and it proposes a solution based on the consideration that juridical laws are for Kant a subclass of moral laws and on the concept of a moral authorization (facultas moralis) of doing what is morally permissible or mandatory and of not doing what is morally forbidden.

Keywords Concept of Kant's Right; Moral Laws and Juridical Laws; Moral Authorization; Principle of Right; Prescriptive Force

Na concepção de Kant, o Direito baseia-se em dois princípios, que podemos tomar, para usar uma terminologia introduzida em outro lugar, como o princípio de avaliação (principium diiudicationis) e o princípio de execução (principium executionis) das ações conformes ao direito (recht). $\mathrm{O}$ primeiro está formulado da seguinte maneira: "Toda ação é direita (ou conforme ao direito, recht) se ela, ou a liberdade do arbítrio segundo a sua máxima, pode coexistir com a liberdade de todos segundo uma lei universal" (MS I, A 33-B 34; Ak. VI, 230). ${ }^{2}$ Kant dá a esse princípio o nome de "princípio universal do Direito", presumivelmente porque: 1) estipula um critério para a aplicação do predicado "direito", servindo assim de fundamento para todos os juízos particulares com que avaliamos a conformidade de nossas ações ao Direito; e também porque: 2) é um princípio fundamental tanto para o Direito privado quanto para o Direito público, que são as duas partes em que se divide o Direito. $^{3}$

$\mathrm{O}$ segundo princípio, Kant enuncia-o da seguinte maneira: "Age externamente de tal maneira que o uso livre do teu arbítrio possa coexistir com a liberdade de todos segundo uma lei universal" (MS I, A 34-B 35; Ak. VI, 231). Kant denomina-o "lei universal do Direito", certamente porque, na sua terminologia, as leis (práticas) são proposições que apresentam uma ação como objetivamente necessária para todo agente dotado de razão. Além disso, visto que essa ação é subjetivamente contingente para agentes

2 A sigla MS remete à Metafísica dos Costumes, que é citada segundo a paginação das edições $\mathrm{A}$ e $\mathrm{B}$, bem como segundo a edição da academia (Ak).

3 A primeira explicação tem a prioridade. Com efeito, é só porque o princípio em questão é um princípio para todos os juízos sobre a retidão jurídica das ações que ele é um princípio básico para todas as partes do Direito. 
imperfeitamente racionais, que nem sempre fazem o que a razão lhes apresenta como objetivamente necessário, Kant formula essa "lei universal do Direito" como um imperativo, que é a forma pela qual as leis práticas se apresentam a um arbítrio imperfeitamente racional.

Embora os dois princípios versem sobre o mesmo objeto (a saber, ações externas compatíveis com a liberdade de todos os demais segundo uma lei universal e por isso mesmo tomadas como conformes ao direito), os dois princípios são claramente distintos, porque o primeiro dá uma regra para a nossa faculdade de julgar, o outro, porém, para o exercício da faculdade de escolher, isto é, o nosso arbitrio.

O conteúdo desses princípios é razoavelmente claro. Se deixarmos de lado no princípio de avaliação (isto é, no "princípio universal do Direito") a referência obscura à máxima da ação externa ${ }^{4}$, o restante do enunciado é razoavelmente claro e suficiente para o seu objetivo, que é o de dar um critério para julgar as ações quanto à sua conformidade ao Direito. Com efeito, ele diz que uma ação externa só é direita (recht) se ela é compatível com a liberdade do arbítrio de todos os demais, e que ela só é compatível com a liberdade dos demais se ela se conforma a uma lei aceitável por todos. Isso posto, o princípio de execução (a "lei universal do Direito") ordena, isto é, diz que devemos agir de tal maneira que nossas ações se conformem a uma lei universal e sejam assim compatíveis com a liberdade de todos os demais.

Embora o enunciado seja bastante claro em si mesmo, o status desses princípios, vale dizer, a razão que temos para aceitar essas proposições como princípios do Direito em geral, está envolto em certa obscuridade e dá ensejo a controvérsias. $\mathrm{O}$ fato de que Kant se refira ao princípio de execução como um "postulado que não é mais passível de qualquer prova" (MS I, A 34-B35; Ak. VI, 231) e, mais à frente, ao que parece, ao princípio de avaliação como um "axioma do Direito" (MS I, § 6, AB 63; Ak. VI, 250)5 não faz muito para

4 Como entender a qualificação: "segundo a sua máxima"? A referência a máximas no princípio do Direito não deixa de surpreender quem supõe, como parece inevitável, que o Direito tem a ver exclusivamente com a "legalidade", isto é, a conformidade de ações externas com leis universais, e não com a "moralidade", isto é, a conformidade das máximas com leis universais, que é a única exigência feita pelas leis éticas ( $M S$ I, $A B$ 13; Ak. VI, 214). A surpresa pode diminuir, porém, se levarmos em conta a afirmação de Kant na mesma passagem segundo a qual as leis jurídicas devem ser consideradas como um caso especial de leis morais. Esse ponto será tratado neste artigo mais à frente, por isso deixarei de lado por enquanto a explicação dessa referência inesperada a máximas na formulação do princípio universal do Direito.

5 Uma confirmação dessa suposição, a saber, que o "axioma do Direito" não é outra coisa senão o "princípio universal do Direito", nós a encontramos numa passagem do artigo sobre "O presumido direito de mentir por amor aos homens", onde Kant diz que uma Metafísica do Direito requer "um axioma, isto é, uma proposição apodicticamente certa, que resulta imediatamente da definição do direito externo (concordância da liberdade de cada um com a liberdade de todos segundo uma lei universal)" (A 311; Ak. 8, 349, grifo no original). 
dissipar essa obscuridade, antes, pelo contrário, aumenta-a, porque exige uma investigação do que Kant entende por "axioma" e "postulado" e que razões ele pode ter para considerar o primeiro princípio como um axioma e o segundo como um postulado - razão por que deixarei de lado neste texto a discussão dessas caracterizações.

No que concerne ao "princípio universal do Direito", a dificuldade está na base para a definição do predicado "direito". Kant baseia-a em três afirmações prévias sobre o conceito do Direito (que Kant caracteriza, aliás, como um conceito moral "na medida em que ele se refere a uma obrigação a ele correspondente" $)$. Tais são: 1) o Direito se aplica às ações externas de um indivíduo, na medida em que elas afetam as ações de outros indivíduos; 2) o Direito concerne às ações externas na medida em que elas envolvem uma relação entre o arbítrio de um com o arbítrio dos demais; 3) o Direito considera unicamente a forma dessa relação e sua compatibilidade com leis universais.

Para essas afirmações, Kant não oferece nenhuma justificativa, pelo menos explícita, nem na passagem citada e nem, que eu saiba, em qualquer outro lugar. Ora, são elas que sustentam a definição do conceito do Direito (tomado substantivamente como suma ou conjunto das leis que resultam de uma legislação externa) ${ }^{7}$, e é dessa definição, por sua vez, que Kant deriva a definição do que é direito (tomado predicativamente como característica das ações externas) no "princípio universal do Direito". Na ausência de uma justificativa explícita, não sabemos que estatuto conferir a essas definições, em particular não sabemos que razão temos para considerá-las como definições reais, isto é, "explicações de coisas (...) suficientes para o conhecimento do objeto", e não como definições nominais, isto é, explicações do "significado que se quis dar arbitrariamente a um certo nome" - como explica Kant em sua Lógica. ${ }^{8}$

No que diz respeito ao segundo princípio, a dificuldade concerne à força do imperativo que formula a "lei universal do Direito" para um poder de escolha imperfeitamente racional. Manifestamente, não se pode tratar de um imperativo hipotético, porque os imperativos hipotéticos comandam sob uma condição subjetiva particular, por conseguinte só valem para quem satisfaz essa condição e por isso mesmo não podem se qualificar como um princípio

7 "O direito é, portanto, a suma das condições sob as quais o arbítrio de um pode ser reunido ao arbítrio de outrem segundo uma lei universal da liberdade" (MS I, AB 33n.; Ak. VI, 230n.).

8 Lógica (ed. Jäsche), § 106, A 222; Ak. IX, 144. 
prático universal, ou seja, como uma lei. Mas tampouco, ao que parece, pode se tratar de um imperativo categórico, porque um imperativo categórico exige não a simples conformidade das ações externas, mas a conformidade das máximas a uma lei aceita por todos, ao passo que a "lei universal do Direito" exige, ao que parece, apenas a conformidade das ações externas, não a de suas máximas. ${ }^{9}$

Diante disso, poderia parecer que a solução seria pura e simplesmente recusar força prescritiva à "lei universal do Direito". ${ }^{10}$ Em favor dessa interpretação, poder-se-ia mobilizar a passagem mesmo em que Kant, após enunciar a lei em questão, afirma que aqui se trata

é verdade de uma lei que impõe uma obrigação, mas de modo algum espera, muito menos exige, que eu próprio, só por causa dessa obrigação, deva restringir a minha liberdade àquelas condições $<$ mencionadas na lei, a saber: a compatibilidade com a liberdade dos demais segundo uma lei universal - GAA>, mas a razão diz apenas que ela está restringida a elas em sua idéia (in ihrer Idee) e a elas também pode licitamente ser restringida pelas vias de fato (tätlich) por outros (MS I, AB 34; Ak. VI, 232, grifos nossos).

Que força prescritiva, pode-se perguntar, pode ter uma lei que não exige, mas apenas diz que a liberdade de cada um está restringida na idéia a uma certa condição?

Essa solução drástica (recusar força prescritiva ao princípio prático do Direito) parece-me, porém, pouco atraente, pelo menos como interpretação do pensamento de Kant, porque colide com outros aspectos importantes da maneira pela qual ele formula sua "lei universal do Direito", em primeiro lugar com a formulação dessa lei como um imperativo, bem como com a afirmação expressa de que essa lei impõe uma obrigação. Com efeito, "obrigação", como explica Kant na Introdução geral, "é a necessidade de uma ação livre sob um imperativo categórico da razão" (MS I, AB 20; Ak. VI, 622), e isso remete-nos de volta à idéia de que a "lei universal do Direito" se exprime por um imperativo categórico, levantando assim, de novo, a dificuldade ainda sem solução.

O que fazer, então, para encontrar uma interpretação coerente do pensamento kantiano? Visto que as dificuldades encontradas dizem respeito,

9 O fato de que o correspondente "princípio universal do Direito" contém uma referência a máximas, e não apenas a ações externas, recomenda prudência quanto a esse ponto. Com efeito, se ambos os princípios têm o mesmo conteúdo, uma referência a máximas têm de estar presente em ambos.

10 Uma defesa vigorosa dessa solução encontra-se em: WILLASCHEK, M. Which imperatives for Right? On the non-prescriptive character of juridical laws in Kant's Metaphysics of morals". In: TIMMONS, M. (Ed.). Kant's metaphysics of morals, interpretative essays. Oxford: Oxford University Press, 2002. 
todas elas, ao estatuto dos princípios do Direito e visto que os princípios do Direito, qualquer que seja seu conteúdo, são, na concepção de Kant, "princípios metafísicos", proponho que um bom ponto de partida para resolver as dificuldades assinaladas poderia ser a consideração do que Kant entende por "princípio metafísico" e de suas observações introdutórias sobre os princípios da Metafísica dos Costumes.

Embora esteja implícita na própria idéia de uma "Metafísica dos Costumes" (isto é, de uma Metafísica moral), da qual a Doutrina do Direito é uma das partes, a noção de um "princípio metafísico" está melhor definida numa passagem da Introdução à $C J$ (seção $\mathrm{V})$ como um princípio que "representa a priori a condição sob a qual apenas objetos cujo conceito tem de ser dado empiricamente podem a seguir (weiter) ser determinados a priori" (A XXVII, B XXIX). ${ }^{11}$

No domínio prático, podemos dizer que os objetos cujo conceito tem de ser dado empiricamente são as ações possíveis para o arbítrio humano. Se isso é verdade, o conceito que tem de ser dado empiricamente é o conceito do poder de escolha humano, que Kant caracteriza como um poder de escolha racional na medida em que este é exercido com base em regras dadas pela razão, mas também como sensitivo na medida em que pode ser afetado por estímulos sensíveis), ${ }^{12}$ isto é, como um poder de querer imperfeitamente racional, que "nem sempre faz algo pela simples razão que lhe é representado que é bom fazê-lo". ${ }^{13}$ Com efeito, que tenhamos um semelhante poder de escolha é algo que só podemos saber empiricamente e, nesse sentido, pode-se dizer que o conceito do arbítrio humano é um conceito empírico.

Não obstante, segundo Kant, é possível determinar a priori a condição sob a qual as ações que dependem do arbítrio humano podem ser caracterizadas como morais, isto é, como boas sem restrição e, por conseguinte, como

11 Os princípios metafísicos encontram-se definidos aí por oposição a "princípios transcendentais", um princípio transcendental sendo definido por sua vez como "aquele através do qual é representada a priori a condição universal sob a qual apenas as coisas podem se tornar objectos de nosso conhecimento em geral".

12 Kant caracteriza o arbítrio humano na MS como um poder de escolha que pode ser afetado, mas não determinado por estímulos sensíveis (MS I, AB 5; Ak. VI, 213; cf. CRP, A 534/B 562). Que ele seja, além disso, um arbítrio livre, isto é, "determinado a ações a partir da vontade pura", é algo que depende da aquisição de uma "competência da razão", que não é outra coisa senão a "faculdade da razão pura de ser prática por si mesma". Que tenhamos semelhante faculdade depende, porém, da consciência da lei moral, portanto de uma determinação a priori do conceito do arbítrio humano pelo conceito da lei moral. Portanto, o conceito do arbítrio humano como afetado, mas não determinado, por impulsos sensíveis é um conceito empírico, mas o conceito do arbítrio humano como livre é um conceito a priori, ou melhor, é um conceito empírico, mas que pode ser determinado a priori como submetido à lei moral.

13 GMS II, BA 39; Ak. IV, 414. O termo usado aí, na verdade, é "vontade" e não "arbítrio", mas essa distinção (só traçada depois) não desempenha nenhum papel aqui, e pode-se aceitar que Kant tem em vista aqui o arbítrio. 
necessariamente boas para todos, a condição da moralidade das ações sendo a conformidade de suas máximas a leis universais, ou válidas de modo geral para todos. Tal é o imperativo categórico, que exige a aptidão das máximas de nossas ações a serem pensadas como uma lei universal. O imperativo categórico é, portanto, um princípio metafísico no domínio prático.

Isso posto, a questão agora é se é possível, dado esse ponto de partida, determinar também a priori a condição sob a qual as ações do arbítrio humano podem ser caracterizadas, não apenas como morais, mas também como direitas (ou conformes ao Direito, ou como quer que se queira traduzir recht).

Certamente, o fato de que o imperativo moral seja um princípio prático metafísico não exclui de antemão a possibilidade de existirem outros princípios metafísicos no domínio prático. Mas, se houver, esses princípios têm de ser pensados como dependentes, ou de alguma maneira subordinados ao imperativo moral, porque o imperativo moral é um imperativo incondicional, isto é, estabelece uma condição restritiva para a realização de qualquer ação e não está submetido ele próprio a nenhuma condição restritiva.

Meu objetivo, porém, é defender a tese de que o princípio, ou antes, os princípios a priori do Direito ${ }^{14}$ são concebidos por Kant não apenas como subordinados ao imperativo moral, mas como derivados deste. Embora o argumento de Kant para mostrar isso não seja inteiramente claro, os dois pontos fundamentais do argumento estão mais ou menos claramente assinalados por Kant. O primeiro ponto é a afirmação de que as leis jurídicas (leis do Direito) são leis morais, isto é, que elas não apenas estão subordinadas a leis morais, mas constituem uma subclasse das leis morais. O segundo ponto é a afirmação de que há um "conceito moral" do direito e a explicação desse conceito como o de uma autorização ou faculdade moral (Befugnis, facultas moralis) de fazer tudo o que é moralmente possível e de resistir pela força a quem quer que tente impedir alguém de fazê-lo.

Que as leis jurídicas constituam uma subclasse das leis morais (juntamente com as leis éticas, que constituem a outra subclasse) está expressamente afirmado por Kant na Introdução geral:

As leis da liberdade se chamam, para serem distinguidas das leis da natureza, morais. $\mathrm{Na}$ medida em que se estendem apenas a meras ações externas e à sua conformidade a leis (Gesetzmäßigkeit), chamam-se jurídicas; mas se elas exigem também que elas (as leis) mesmas sejam as razões determinantes das ações, então elas são éticas, e

14 Visto que, ao contrário do que se passou com a lei moral (que é ao mesmo tempo um princípio para julgar a moralidade das máximas e a injunção de agir com base em máximas morais), Kant decidiu formular separadamente o princípio de dijudicação do princípio de execução. 
dizemos conseqüentemente que a concordância com as primeiras é a legalidade (Legalität), a concordância com as segundas a moralidade da ação (MS I, AB 7; Ak. VI, 214).

A conceituação das leis jurídicas como leis morais envolve uma dificuldade óbvia. Se quisermos conceber as leis jurídicas como sendo de fato apenas uma espécie particular de leis morais, então temos de estar prontos para admitir que elas têm por princípio superior o imperativo categórico, que é (como lembrado na alínea imediatamente anterior à passagem citada) o princípio supremo das leis morais. Nossa questão inicial, porém, e ainda sem solução é: tem sentido admitir o imperativo categórico como princípio de leis que exigem tão somente a "legalidade", isto é, a conformidade das ações externas a leis universais? Até certo ponto é possível dar uma resposta afirmativa a essa questão, visto que podemos pensar a conformidade a leis universais como dependente de um interesse não moral (é o que admite Kant alhure ${ }^{15}$ ). Ao conceito do imperativo categórico pertence, porém, não apenas a idéia da conformidade a leis universais, mas também a idéia de uma conformidade incondicional, ou por respeito a essas leis. Mas, então, como podem as leis jurídicas serem pensadas como uma espécie particular das leis morais se elas excluem uma nota essencial do conceito destas últimas (qual seja, a conformidade incondicional a leis)? ${ }^{16}$

A distinção entre leis morais e leis jurídicas é retomada em outra passagem da Introdução geral (na secção III), onde encontramos, ao que parece, uma resposta para essa dificuldade. Kant propõe nessa passagem que consideremos o modo pelo qual as leis são estabelecidas, isto é, sua "legislação". A toda "legislação", lemos aí, pertencem essencialmente dois elementos: a enunciação de uma "lei" e a indicação de uma "mola propulsora" (ou "móbil", "incentivo", Triebfeder). A lei apresenta uma ação como objetivamente necessária, isto é, como um dever. A "mola propulsora" conecta à representação da lei uma razão que determina subjetivamente o arbítrio a agir. ${ }^{17}$ Isso posto, Kant prossegue para explicar que a mesma lei pode ser legislada com base em molas propulsoras diferentes. A legislação que faz da ação representada um dever é a legislação ética, diz Kant, e aquela que "também admite" (a expressão é de Kant) uma outra mola propulsora, além da idéia do dever, é a

15 GMS II, BA 71 et seq.; Ak. IV, 431 et seq.

16 A concepção das leis morais como incluindo em sua esfera tanto as leis jurídicas quanto as leis éticas envolve também dificuldades para a distinção entre as leis éticas e as morais. Mas disso não tratarei aqui, por estar fora do tema deste texto.

17 MS I, AB 14 et seq.; Ak. VI, 218 et seq. 
legislação jurídica. Assim, poderíamos dizer que há uma certa ambivalência, ou sobreposição de motivos na legislação jurídica, pois ela representa uma ação como objetivamente necessária, isto é, como um dever, e diz que devemos realizá-la seja simplesmente porque é um dever, seja por uma outra razão qualquer, capaz de determinar subjetivamente a nossa vontade. Qual é essa mola propulsora adicional fica claro na frase seguinte, onde Kant explica que ela deve ser extraída, não exatamente de nossas inclinações (Neigungen), mas antes de nossas aversões (Abneigungen), porque se trata, no caso das leis jurídicas, de uma legislação que é necessitante (nötigend), e não de um engodo (Anlockung), que é convidativo (einladend) ${ }^{18}$ - querendo dizer, por outras, que as leis jurídicas ordenam algo sob pena do uso da força, seja para evitar, seja para punir a não-conformidade.

Vejamos agora se nossa dificuldade pode ser afastada por essa maneira de distinguir leis morais e leis jurídicas. Perguntávamos: como é que as leis jurídicas podem ser pensadas como uma espécie particular das leis morais, uma vez que elas excluem uma nota essencial do conceito destas últimas, a saber, a exigência de uma conformidade incondicional? A resposta que encontramos no texto lido com atenção é que, na verdade, não excluem a conformidade incondicional. Com efeito, segundo a explicação dada, as leis jurídicas exigem, sim, a mera legalidade "sem consideração das molas propulsoras" 19 , e isso significa que elas exigem a conformidade às leis quer esta seja motivada pela idéia do dever, quer pela aversão às conseqüências da não-conformidade.

Obviamente, nenhuma lei prática pode ser pensada como sendo, ou como se exprimindo, ao mesmo tempo, através de um imperativo categórico e de um imperativo hipotético. Mais do que um hibridismo, isso seria uma verdadeira contradictio in adiecto. Contudo, podemos pensar sem contradição: 1) que aquilo que é exigido incondicionalmente pela lei moral possa também ser imposto pela força e obedecido sob a condição de se querer evitar a imposição da força; 2) que a imposição seja legítima, isto é, um direito que nos é dado pela própria lei moral. Assim, as leis jurídicas podem ser caracterizadas como leis que exigem o que pode ser exigido moralmente de todos, portanto incondicionalmente (e é nesse sentido que as leis jurídicas são, sem mais, leis morais), mas que o exigem também daqueles que, embora saibam o que a lei moral exige deles, não querem se conformar a ela, e só o fazem sob a condição 
de seu interesse privado ou se forem coagidos a isso (e é nesse sentido que elas constituem uma subclasse das leis morais).

Creio que essa interpretação encontra apoio em duas teses de Kant. A primeira é a tese geral, formulada en passant é verdade e em outro contexto, mas não menos explícita, de que a todo dever corresponde um direito. ${ }^{20} \mathrm{Com}$ efeito, "direito" significa aqui, na terminologia mesmo de Kant, a autorização ou faculdade moral (Befugnis, facultas moralis) de fazer não só o que é exigido como dever, mas também o que é lícito, assim como a de não fazer o que é proibido. A segunda é a tese explicitamente defendida no $\S \mathrm{E}$ da Introdução à doutrina do Direito, onde Kant demonstra que "o direito está conectado à faculdade moral de usar a coação" (MS I, AB 35; Ak. VI, 231). Se aceitamos isso, podemos dizer que a legislação jurídica é tornada possível pela própria moralidade, ou, por outras, que o direito é fundamentalmente o direito moral de coagir (pelo uso ou ameaça do uso da força) aquilo que é exigido por uma lei moral, toda vez que somos impedidos seja de fazer o que é lícito ou obrigatório, seja de não fazer o que é proibido.

Como já concedido, as duas teses só são introduzidas posteriormente, em outros contextos e para responder questões diferentes. Mas elas não se baseiam em qualquer suposição que tornaria impossível fazer uso delas em outros contextos. $\mathrm{Na}$ verdade, elas podem ser fundamentadas no mero conceito do que é lícito (isto é, moralmente possível), que é um conceito básico da Introdução geral e pertence, portanto, às duas partes da Metafísica dos Costumes ("Direito" e "Ética"). Assim, não vejo mal algum em recorrer a essas teses a fim de explicar a concepção moral do direito e das leis jurídicas.

O passo seguinte, em meu argumento, deveria ser o de mostrar como a concepção moral das leis jurídicas dá uma base para resolver nossas dificuldades iniciais sobre o estatuto dos princípios do Direito em Kant. Mas, antes de passar a isso, é preciso afastar uma dificuldade para a interpretação dada. Com efeito, parece possível alegar que é tão-somente no estado de natureza, anterior à criação de Estados políticos, que podemos identificar as leis do Direito a (uma espécie de) leis morais. Assim, pode-se conceder facilmente que, num presumido estado de natureza, a conformidade a leis universais só pode ser pensada como conformidade a leis morais, visto que por hipótese ainda não há leis positivas. Numa sociedade política, porém, a conformidade exigida pelas

20 Embora de uma maneira alusiva apenas na pergunta: "Por que, no entanto, a doutrina dos costumes (Moral) é intitulada (nomeadamente por Cícero) a doutrina dos deveres e não também dos direitos? uma vez que uns remetem (sich beziehen auf) aos outros" (MS I, AB 48; Ak. VI, 240). A colocação do ponto de interrogação mostra que Kant assume por conta própria a suposição de que dever e direito se implicam mutuamente. 
leis jurídicas é precisamente a conformidade a leis positivas. Por essa razão, nossa interpretação teria no máximo um valor limitado, como uma explicação da concepção kantiana das leis do Direito natural numa condição anterior à vida em sociedades políticas.

Essa dificuldade pode ser facilmente superada no contexto da Metafísica moral kantiana. Com efeito, se não apenas a noção do Direito, mas também a noção de um Estado político, pode ser introduzida e investigada num quadro metafísico (isto é, envolvendo tão somente princípios a priori), essas noções têm de ter uma origem a priori e têm de ser derivadas, como a noção de lei jurídica, de exigências morais. Mas se a idéia de um Estado político tem sua raiz numa exigência moral (todas as leis que se podem pensar como derivadas de um Estado político correspondendo a essa idéia), logo todas as leis positivas, terão o mesmo status que as leis do Direito natural, isto é, terão de ser pensadas como especificações de leis morais. Mais ainda: mesmo se, numa hipótese contrária, a noção de um Estado político tivesse de ser introduzida, não no quadro de uma Metafísica moral, baseada em princípios $a$ priori, mas no quadro de uma Antropologia moral, que tem a ver unicamente com as condições empíricas que podem favorecer ou dificultar a aplicação dos princípios a priori da Moral e do Direito, mesmo assim, as leis positivas teriam de ser pensadas como necessariamente subordinadas a leis morais, embora não derivadas delas, e isso pela simples razão de que não pode haver, como argumenta Kant na Introdução da $M C$, um verdadeiro conflito de deveres, uma vez que ações exigidas por regras opostas não poderiam ser igualmente necessárias. ${ }^{21}$ Portanto, como quer que a noção de um Estado político deva ser tratada na filosofia prática (seja como conseqüência de uma exigência moral, seja como o fruto de considerações pragmáticas), o fundamento moral das leis positivas parece estar garantido, desde que, bem entedido, possam ser consideradas efetivamente como leis do Direito (e não regras impostas pela força).

Podemos ver agora se a concepção kantiana das leis jurídicas como leis morais dá, como aleguei, uma base para resolver as dificuldades iniciais acerca dos dois princípios fundamentais do Direito. Consideremos primeiro, seguindo a ordem da exposição kantiana, o "princípio universal do Direito". Como vimos, Kant baseou a formulação desse princípio em três afirmações não argumentadas sobre a extensão do conceito do Direito, quais sejam, para recordar: 1) que o Direito se aplica às ações externas de um indivíduo na 
medida em que elas afetam as ações de outros indivíduos; 2) que o Direito concerne às ações externas na medida em que elas envolvem uma relação do arbitrio de um com o arbitrio dos demais; 3) que o Direito considera unicamente a forma dessa relação e sua compatibilidade com leis universais. Para essas afirmações não ofereceu, como observado, nenhuma justificativa, razão por que o conceito e a formulação do princípio baseado nesse conceito parecem ficar no ar.

Como também já observado, Kant alude ao conceito do Direito que está em jogo aqui como o conceito "moral" do Direito, por extenso: como "o conceito do Direito na medida em que se refere a uma obrigação a ele correspondente, isto é, o conceito moral do mesmo" (MS I, AB 32; Ak. VI, 230). Esse conceito é dado como conhecido, visto que não é explicado na passagem em pauta, e podemos admitir que, ao se referir a ele, Kant tem em vista a explicação já dada das leis jurídicas como uma subclasse das leis morais. Ora, esse conceito das leis jurídicas como uma espécie das leis morais está baseado, para recordar, na idéia de que o direito é a autorização ou faculdade moral: 1) de realizar o que é lícito e o que é obrigatório e de não fazer o que é proibido; e 2) de coagir pela força quem nos impede de fazê-lo. Se isso é concedido, creio que as três afirmações sobre a extensão do conceito do Direito resultam de uma consideração sobre os limites da coação legítima, isto é, daquilo a que se pode legitimamente coagir as pessoas que não realizam os seus deveres para com os demais.

Com efeito, pode-se argumentar aí da seguinte maneira: primeiro, que uma pessoa só pode ser coagida à realização de atos externos (não à adoção de máximas e atitudes). Segundo, que ela só pode ser coagida a atos externos que afetam o uso do arbitrio dos demais, porque, por hipótese, se trata de coagi-la a respeitar em seus atos o direito dos demais de fazer o lícito e o obrigatório, bem como o direito de não fazer o proibido. Terceiro, que essa pessoa só pode ser coagida a atos externos que sejam conformes a leis morais que, enquanto leis da liberdade, asseguram a compatibilidade do arbítrio de todos, pois, de outro modo, a coação não seria legítima, isto é, algo facultado moralmente. Mas essas são precisamente as afirmações nas quais Kant baseia a formulação do seu "princípio universal do Direito". Se isso é verdade, a interpretação dada (da concepção moral das leis jurídicas) tem a vantagem adicional de suprir as justificativas que o leitor atento, com razão, reclama para as afirmações em pauta.

Consideremos agora a "lei universal do Direito", isto é, o imperativo que comanda: "Age externamente de tal maneira que o livre uso do teu arbítrio possa coexistir com a liberdade de todos segundo uma lei universal" (MS I, 
A 34-B 35; Ak. VI, 231). A dificuldade com esse princípio concernia, como vimos, à força prescritiva desse imperativo, que não podia ser concebido nem como um imperativo hipotético, porque perderia sua validade incondicional para todos, nem como um imperativo categórico, porque teria enquanto tal de exigir a conformidade dos princípios subjetivos (isto é, das máximas) e não apenas a conformidade das ações externas.

É fácil ver agora que essa dificuldade também pode ser solucionada com base no "conceito moral do Direito", tal como interpretado. De fato, segundo essa interpretação, as leis jurídicas resultam de uma especificação das leis morais, pois elas são, antes de mais nada, as leis morais que pressupomos válidas para todos (como princípios objetivos), mas que admitimos (a priori) que podem não ser o princípio subjetivo de todos os indivíduos e para as quais nos arrogamos por isso mesmo o direito (a faculdade moral) de impôlas pela força a todo aquele que não as respeita ao interagir conosco. Eis por que é possível dizer, por um lado, que as leis jurídicas, leis morais que são, "impõem uma obrigação" válida enquanto tal para todos como um imperativo categórico (pois, como já notado, a "obrigação é a necessidade de uma ação livre sob um imperativo categórico da razão") (MS I, AB 20; Ak. VI, 622). Mas eis por que também se pode dizer, por outro lado, que as leis jurídicas dizem a quem não estiver disposto a realizar espontaneamente essa obrigação que ele deve realizá-la de qualquer modo se não quiser coagido.

Por mais claro que isso seja, isso não basta ainda para nos desembaraçar de todas as nossas dificuldades, uma vez que o texto de Kant contém formulações que sugerem uma interpretação não prescritivista da "lei universal do Direito". Consideremos, primeiro, a afirmação de Kant que a "lei universal do Direito" diz apenas que a liberdade está restringida a uma certa condição em sua idéia, e que parece sugerir uma leitura não prescritivista. Mas, se lemos cuidadosamente, podemos ver que é precisamente o contrário que Kant tem em vista. Com efeito, dizer da liberdade (ou da vontade, ou do arbítrio) que ela está restringida em sua idéia a uma certa condição é o mesmo que dizer, na linguagem kantiana, que ela deve restringir-se, mesmo que de fato ela não se restrinja a essa condição. Em Kant, a expressão "na idéia" contrasta com "realmente" ou "de fato" e serve precisamente para opor o que deve ser ao que realmente é. Em outras palavras, serve precisamente para caracterizar ações objetivamente necessárias como ações que são subjetivamente contingentes para agentes imperfeitamente racionais e que, por isso, aparecem a estes como algo que deve ser e encontra no modo imperativo sua expressão lingüística adequada. 
A outra asserção de Kant, segundo a qual a lei moral "de modo algum espera, muito menos exige, que eu próprio, só por causa dessa obrigação, deva restringir a minha liberdade àquelas condições" (grifos no original), parece muito mais difícil de conciliar com a interpretação dada. Contudo, duas considerações podem mostrar o contrário. A primeira é que o objetivo da legislação jurídica é lidar com pessoas que não se conformam a leis válidas para todos e infringem o direito moral de fazer o que é moralmente possível. Visto que ela tem em vista quem não se conforma espontaneamente a leis, não faz sentido exigir deste que restrinja por si mesmo sua liberdade (isso seria exortação moral ou pregação da virtude, como explica Kant). Mas isso não significa que a "lei universal" não faça nenhuma exigência e não seja prescritiva. Com efeito, isso se torna claro se prestamos atenção na oração como um todo (e esta é minha segunda consideração). Lida em sua integralidade, a afirmação de Kant é, em suma, que a lei não exige que eu restrinja, eu próprio, espontaneamente, a minha liberdade, mas diz que minha liberdade está restringida em sua idéia - e vimos que isso significa precisamente que a lei universal do Direito diz que devo restringi-la, e por isso ordena fazê-lo, mesmo que (podemos acrescentar) de fato não o faça.

Com efeito, podemos observar, para concluir: seria realmente surpreendente se as leis jurídicas, que Kant introduziu como uma modalidade das leis morais, devessem ser consideradas não prescritivas. Isso, sim, seria de fato uma contradictio in adiecto, visto que as leis morais, de que as leis do Direito são uma espécie, valem contrafactualmente, "em sua idéia", e por isso mesmo se exprimem através de imperativos como um dever. 